\title{
Obstacles to Efficient Education Online: Interview with Associate Professor Dr. M. Murat Erguvan
}

Andrew Bula (Corresponding author)

Centre for Foundation \& Interdisciplinary Studies, Baze University, Abuja, Nigeria

Email: andrew.bula@bazeuniversity.edu.ng

Received: 28/07/2021

Accepted: 14/09/2021

Published: 01/11/2021

Volume: 2 Issue: 6

How to cite this paper: Bula, A. (2021). Obstacles to Efficient Education Online: Interview with Associate Professor Dr. M. Murat Erguvan. Journal of Practical Studies in Education, 2(6), 23-24

DOI: https://doi.org/10.46809/jpse.v2i6.36

Copyright $\odot$ by author(s) and Global Talent Academy Ltd. This work is licensed under the

Creative Commons Attribution International License (CC BY 4.0).

http://creativecommons.org/licenses/by/4.0/

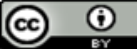

\begin{abstract}
Associate Professor Dr. M. Murat Erguvan has 28 years of teaching and administrative experience in various countries and positions such as programme coordinator, dean, vice rector for education, research and/or external affairs. He has been with the International Black Sea University (IBSU), in Tbilisi, Georgia, a country located at the convergence of Eastern Europe and Western Asia since 2012, and has occupied the positions of the Head of Total Quality Management \& Strategic Planning Office (TQM), International Relations Office (IRO), and Vice Rector for Education and Research. Murat earned his doctoral degree in Education Management: "A Framework for Implementation of Total Quality Management in Georgian Higher Education Institutions in the Context of International Black Sea University". Currently, he offers Quality Management classes at bachelor's and master's levels, as well as Using Instructional Technology in Education classes to bachelor's and master's students. Besides coordinating bachelor's and master's theses, this professional educationist supervises the work for strategic planning and takes part in producing information system modules by developing database structures. In addition, he has taken part in ISO 9001:2008 implementation in higher education institutions, and received EFQM Assessor Training in Brussels. In this interview, therefore, Murat converses with Andrew Bula, a lecturer at Baze University, Abuja, Nigeria, on the current state of online education around which he remains committed.
\end{abstract}

Keywords: Education, Online Learning, Technology, Challenges, Coronavirus, Curriculum

$\mathbf{A B}^{1}$ : It's a pleasure speaking with you, Sir, and I'm equally pleased that you can grant this interview.

ME²: The pleasure's mine.

AB: Technology has for a very long time supported formal education, and with the existence of the novel Coronavirus pandemic the world over, which case escalated last year and has dragged on to this moment, I wonder what might be your thinking regarding the state of education? I mean online learning is largely the norm now, even in my part of the world Nigeria; and so, I wonder what might be your general assessment of its viability?

ME: You are definitely right in saying that video conferencing tools are part of our educational lives now if not our business lives as well about not only tech challenges but also human resource challenges related to instructional design and 
e-learning / teaching skills. Now, both the students and the teaching body suffer from it; however, the transition was necessary.

AB: Is there need to work out a curriculum tailored to meet the demands of online learning, especially, heaven forbid, if this trending pandemic situation gets out of hand?

ME: The curriculum building and updating issue has always been in the agenda, and, together with the pandemic, the process has gained a new dimension. It is naturally not possible to follow a general approach for all types of courses.

AB: Education, formal education I mean, comes with peculiarities in each of the diverse contexts and locales across the world, even in Europe and America. For us, in my university in Nigeria, part of the experiences as well as the challenges is the occasional non-availability of internet access and power outage, which happens sometimes at crucial moments in the course of lecturing students online. Could this be what obtains at your location too?

ME: We thankfully do not face such an issue except for very few students who happen to live in remote villages. I believe maintaining good internet connection is a governmental responsibility. There are, however, renowned tech companies and NGOs that strive to provide internet connection to disadvantaged communities. Building the infrastructure is not easy and may take time; and, meanwhile, some students will definitely suffer.

AB: And what about the necessity of feedback in online learning?

ME: Feedback is a must in both on-site and online learning. There are free LMS solutions such as Moodle which can be used to offer the classes, do the assessment, and receive or send feedback.

AB: I'm well aware that nowadays emphasis on education is placed on functionality. Which is, in fact, why I wonder how students might be made to take part in practical exercises online despite the marvels of technology. Yes, indeed I know that some courses - within the domains of English Language and Literature, for instance, can be more easily managed in online teaching. But I'm here disquieted about those practically oriented ones in the sciences. Sir, your position on this, please.

ME: I believe a certain distinction must be made based between practical and theoretical courses. Theoretical courses will definitely be easier to integrate into the new way of teaching, but the practical ones have to be revised on a case-by-case approach. Unfortunately, the solution for practical courses can be very expensive and there is no easy way out except for inviting the students to the higher educational institutions for a certain period of time under strict Covid rules and conditions.

AB: Do you agree with me that with online learning the chance of hidden curriculum is almost utterly, or, indeed, completely extinguished?

ME: Yes and no. Online interaction has now become the norm. Therefore, yes: because we have lost the physical interaction that we will always miss, and no: because we have new online interaction tools on our tech devices.

AB: The novel Coronavirus pandemic has continued to be a terrible situation in the world, but thank you Dr. M. Murat Erguvan for your time.

ME: Thank you for involving me in this timely research.

\section{Endnotes}

\footnotetext{
${ }^{1}$ Andrew Bula

${ }^{2}$ Associate Professor Dr. M. Murat Erguvan
} 